\title{
Marco Girolamo Vida, De arte poetica. Art poétique
}

\section{Filippo Fassina}

\section{Q OpenEdition}

\section{Journals}

\section{Edizione digitale}

URL: http://journals.openedition.org/studifrancesi/2104

DOI: $10.4000 /$ studifrancesi.2104

ISSN: 2421-5856

\section{Editore}

Rosenberg \& Sellier

\section{Edizione cartacea}

Data di pubblicazione: 1 aprile 2014

Paginazione: 128-129

ISSN: 0039-2944

\section{Notizia bibliografica digitale}

Filippo Fassina, « Marco Girolamo Vida, De arte poetica. Art poétique », Studi Francesi [Online], 172 (LVIII

| I) | 2014, online dal 01 avril 2014, consultato il 18 septembre 2020. URL : http://

journals.openedition.org/studifrancesi/2104; DOI : https://doi.org/10.4000/studifrancesi.2104

\section{Questo documento è stato generato automaticamente il 18 settembre 2020.}

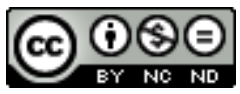

Studi Francesi è distribuita con Licenza Creative Commons Attribuzione - Non commerciale - Non opere derivate 4.0 Internazionale. 


\title{
Marco Girolamo Vida, De arte poetica. Art poétique
}

\author{
Filippo Fassina
}

\section{NOTIZIA}

MARCo GIROLAMO VIDA, De arte poetica. Art poétique, édition et traduction par Jean Pappe, Genève, Droz, 2013 («Cahiers d'Humanisme et Renaissance», 111), pp. 244.

1 Appartenente alla letteratura cinquecentesca in lingua francese, ma di un testo in latino, è opportuno segnalare ugualmente questa pubblicazione, considerato l'enorme successo che ebbe in Francia il testo qui edito. Si tratta del De arte poetica di Marco Girolamo Vida. In questo lavoro, dopo aver fornito alcune precise indicazioni biografiche sull'autore, viene presentata l'edizione del testo latino attraverso un'ampia introduzione che descrive le caratteristiche e le peculiarità dell'opera: si tratta fondamentalmente di un'epistola in esametri dattilici dedicata al Delfino di Francia, Francesco e pubblicata nel 1527 (una prima edizione del 1517 non fu mai pubblicata), con la finalità di istruire il futuro sovrano sui generi letterari più importanti, in particolar modo sull'epica. L'A. sottolinea come i principali modelli di questo testo siano l'Ars poetica di Orazio, la Silva Nutricia di Poliziano e l'Institutio oratoria di Quintiliano. Vengono, inoltre, descritti i principali nuclei tematici dell'opera: l'ispirazione intesa come calor di matrice retorica, l'imitatio che non può essere disgiunta dalla vraisemblance, il ruolo fondamentale dei modelli, in particolar modo quelli greci. Viene, infine, introdotta la nozione di storia intesa da Vida come progresso realizzato grazie all'esperienza dei predecessori. Il debito nei confronti di Virgilio è evidente, e ribadisce lo stretto rapporto con i classici che permea tutta l'Ars poetica, ma che lascia, allo stesso tempo, spazio ad alcune tematiche che potrebbero essere definite pre-barocche, come la varietas e l'uso molto frequente delle metafore. Un ultimo paragrafo è dedicato all'epica e alla visione fondamentalmente catastrofista della storia, che potrebbe sembrare in contraddizione con il modello virgiliano, ma che in realtà si integra perfettamente in una visione articolata e disincantata delle vicende 
umane. Del testo, oltre all'edizione, viene fornita la traduzione completa a fronte e alcune note esplicative. 